\title{
The pims and outs of survival signaling: role for the Pim-2 protein kinase in the suppression of apoptosis by cytokines
}

\section{Eileen White}

Howard Hughes Medical Institute, Center for Advanced Biotechnology and Medicine, Department of Molecular Biology and Biochemistry, Cancer Institute of New Jersey, Rutgers University, Piscataway, New Jersey 08854, USA

The regulation of cell survival has a well-documented role in the maintenance of homeostasis, the damage response, and is misregulated in various disease states. Cancer, in particular, is one disease in which the failure to maintain an intact apoptotic response is associated with disease progression and treatment failure /Cory and Adams 2002). Apoptosis is regulated, in part, through dependence upon growth factors and cytokines. For example, the survival of lymphoid cells is closely controlled by specific cytokines, which provide an intricate selection process to determine the cells that should be maintained and those that should not. Whereas this cytokine and growth factor addiction can be thought of as an effective means for controlling populations of normal proliferating cells, cells do occasionally escape this dependence, often through specific defects in the capacity to undergo apoptosis, or the upstream signal transduction pathways that regulate apoptosis, and the result can be tumorigenesis. Thus, understanding how the cytokine and growth factor signaling pathways regulate survival is an integral step toward the development of effective cancer treatments.

Growth factors and cytokines signal survival through their cognate receptors, activating signaling pathways often composed of protein kinase cascades, the most notorious of which include the Map kinases, Jak/Stat, PI3 kinase/Akt, and IKK/NFкB. Through the phosphorylation of specific substrates, survival activity can be manifest in a myriad of ways spanning regulation of transcription through direct modification of apoptotic effectors.

There are a large number of growth factors and cytokines, some of which provide survival signals specific to certain cell types, whereas others posses more ubiquitous survival functions. Many share a number of common kinase signaling pathways, and it is merely the mechanism of pathway activation that determines specificity of the survival signal. There is also cross-talk, overlap, and redundancy to many survival signaling path-

E-MAIL ewhite@cabm.rutgers.edu; FAX (732) 235-5795. Article and publication are at http://www.genesdev.org/cgi/doi/10.1101/ $\operatorname{gad} .1123103$. ways that impose layers of complexity to the process of defining the crucial mechanisms of survival regulation in normal and diseased cells. In this issue, Fox et al. (2003) use a genomics approach to explore the role of one serine/threonine kinase, Pim-2, in growth factor-mediated apoptotic resistance in hematopoeitic cells.

\section{Pim-2 is regulated by IL-3}

To identify the mechanism of survival signaling by interlukin-3 (IL-3) in lymphoid cells, Fox et al. (2003) used microarray gene expression profiling to screen the IL-3dependent lymphoid B-cell line FL5.12 for alterations in gene expression upon IL-3 withdrawal. FL5.12 cells are exquisitely IL-3 dependent and undergo apoptosis when factor deprived, but can be rescued by over expression of pro-survival members of the Bcl-2 family such as Bcl-2 or Bcl- $\mathrm{x}_{\mathrm{L}}$. Of the 9500 genes examined, in IL-3-deprived cells the most down-regulated gene was pim-2, as confirmed by Northern analysis of the pim-2 message (Fox et al. 2003). Pim-2 thereby emerged as a particularly interesting candidate for a mediator of survival signaling by IL-3.

\section{Pim kinases and cancer}

Pim-2 is a member of a family of serine/threonine protein kinases that consists of two other members, Pim-1 and Pim-3 (Mikkers et al. 2002). Pim-2 protein levels and kinase activity were depressed dramatically in FL5.12 cells upon IL-3 withdrawal, and Pim-2 inhibits apoptosis normally induced in cells deprived of IL-3 (Fox et al. 2003). Finally, Pim-2 knock-down experiments, or overexpression of a Pim-2 dominant-negative mutant, prevented effective survival signaling by IL-3, supporting a role for Pim-2 as a mediator of apoptosis inhibition by IL-3.

The implication of Pim-2 in cytokine survival signaling is of particular interest in light of its previous known role in promoting lymphomagenesis. In work largely pioneered by Anton Berns and colleagues (Allen and Berns 1996), retroviral insertional mutagenesis initially identi- 
fied pim-1, and then later pim-2 and pim-3, as genes coactivated with myc in murine lymphoid tumors (Breuer et al. 1989; van der Lugt et al. 1995; Mikkers et al. 2002). Conformation of the role of pim-1 or pim-2 collaboration with myc in B-cell tumorigenesis was demonstrated in

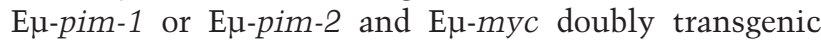
mice in which oncogene expression occurs in the B-cell lineage. Whereas E $\mathrm{\mu}-\mathrm{myc}$ mice develop lymphomas by 3

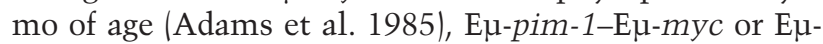
pim-2-Eu-myc compound transgenic mice display greatly accelerated formation of lethal B-cell tumors, to which they succumb perinatally (Verbeek et al. 1991; Allen et al. 1997). Interestingly, both pim-1 and pim-2 are known to be responsive to cytokines, and some evidence suggests a role for Pim-1 in survival signaling. The mechanism by which Pim kinases promote the development of lymphoid tumors, however, remains to be determined. The new evidence presented by Fox and colleagues (Fox et al. 2003) suggests that Pim-2 functions to promote cell survival mediated by IL-3, and that inappropriate Pim-2 activation may block apoptosis, thereby providing a possible mechanism for enhancement of Myc oncogenisity.

\section{Myc, apoptosis, and lymphomagenesis}

Deregulation of myc has long been known to promote cell proliferation and oncogenesis, but in the process, renders cells profoundly growth factor dependent (Askew et al. 1991; Evan et al. 1992). Whereas normal cells growth arrest when deprived of the appropriate growth factors and cytokines, those with deregulated myc continue to proliferate and undergo apoptosis. Thus, tumor formation induced by deregulated myc is greatly facilitated by abrogation of apoptosis, which can be accomplished by overexpression of an anti-apoptotic protein such as Bcl-2 (Vaux et al. 1988; Strasser et al. 1990; Fanidi et al. 1992).

Bcl-2 and its surrogate Bcl- $\mathrm{x}_{\mathrm{L}}$ block apoptosis by interacting with pro-apoptotic members of the Bcl-2 family, either the BH3-only proteins such as Bad, Bim, Bid, and Puma, or the downstream effectors of cell death Bax and Bak (Cory and Adams 2002). Induction or activation of $\mathrm{BH} 3$-only proteins either antagonizes the function of pro-survival members of the Bcl-2 family such as Bcl-2, or directly activates pro-apoptotic Bax and Bak. Either way, the integrity of the mitochondrial outer membrane becomes compromised, promoting the release of apoptogenic factors such as cytochrome $\mathrm{c}$ and Smac/Diablo that facilitate the activation of downstream caspases, thereby promoting apoptotic cell death. Mutational events that inactivate apoptosis upstream, at, or downstream of mitochondria have all been implicated in the development of human tumors. Bcl-2 overexpression, in particular, plays a major role in the genesis of many human tumors, and understanding alternate means for apoptotic blockade that occur in other tumors is an important area of investigation.

The p53 tumor-suppressor protein is an effector of apoptosis in response to deregulated $m y c$, and analogously to Pim-2 activation, p53 deficiency greatly accelerates lymphomagenesis of the E $\mathrm{k}-\mathrm{myc}$ transgenic mice (Eischen et al. 1999; Schmitt et al. 1999). Furthermore, some evidence suggests that it is the apoptotic activity of p53 that is responsible for suppression of Myc-mediated lymphomagenesis (Schmitt et al. 2002). Although the precise mechanisms by which p53 induces cell death, and there may be many, has not been definitively determined, it is a potent transcriptional activator of the gene encoding the pro-apoptotic $\mathrm{BH} 3$-only protein Puma, the loss of which impairs p53-mediated apoptosis (Yu et al. 2003). Direct demonstration of the p53-mediated apoptotic pathway responsible for tumor suppression, however, awaits the generation of a p53 effector-deficient mouse that displays a tumor-prone phenotype.

\section{How does Pim-2 promote survival?}

The functional complementation of E $\mu-m y c$ tumorigenesis with Bcl-2 or Pim-2 gain-of-function, or p53 loss-offunction models suggests that a common ability to suppress apoptosis may be critical for tumorigenesis. It is interesting to note that Pim-2 overexpression promotes survival long term and not only to IL-3 deprivation, but to a myriad of other toxic stimuli (Fox et al. 2003). This suggests that at least one Pim-2 target is common to many apoptotic pathways. A good starting point would be to determine whether Pim-2 blocks apoptosis signaled through mitochondria, and if so, whether it promotes survival by acting upstream or downstream of mitochondria. The pro-apoptotic BH3-only protein, Bad, is, in fact, phosphorylated by Pim-2 (Fox et al. 2003), a process known to prevent Bad-Bcl- $\mathrm{x}_{\mathrm{L}}$ interaction and apoptosis (Datta et al. 2002). It will be of interest to determine whether Bad deficiency is functionally equivalent to Pim-2 gain-of-function in terms of apoptosis inhibition and enhancement of E $\mu-m y c$ lymphoid tumorigenesis.

The implication from the observation that both Pim-2 activation and p53 deficiency cooperate with deregulated $m y c$, is that inappropriate Pim-2 activation could interfere with this Myc-mediated, p53-dependent apoptotic process. Given this p53-dependence of Myc-mediated apoptosis, it will be worthwhile to test Pim-2 for inhibition of p53-mediated apoptosis (Fig. 1). If so, Pim-2 could prevent either the induction of Puma by p53 or prevent Puma pro-apoptotic function. Alternatively, Pim-2 may inhibit other proposed mechanisms for p53-mediated apoptosis.

Another Bcl-2 family member worth examining as a Pim-2 target is Bim (Fig. 1). Pro-apoptotic Bim is a BH3only protein that is a Bcl-2 antagonist (Bouillet et al. 2001), and Bim has been shown to be regulated by phosphorylation (Weston et al. 2002; Lei and Davis 2003). Interestingly, Bim is also up-regulated at the mRNA and protein level upon IL-3 withdrawal (Shinjo et al. 2001), and cells from bim-deficient mice are resistant to apoptosis induced by cytokine depravation (Bouillet et al. 1999, 2001). Furthermore, cytokine withdrawal has been shown to reduce bim transcription through inactivation of the transcription factor forkhead via the PI3 kinase/ 


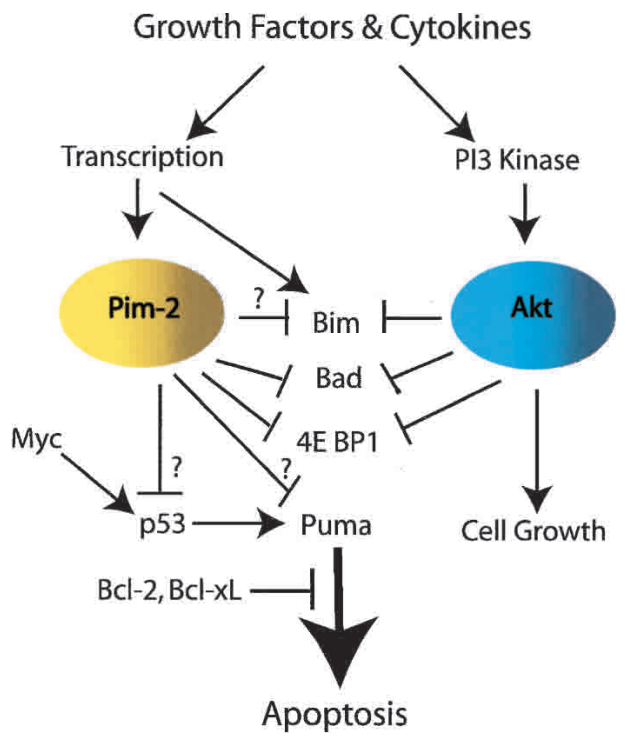

Figure 1. Survival signaling pathways regulated by Pim-2 and Akt. See text for explanation.

Akt pathway (Dijkeers et al. 2002). It will be of interest to test whether Bim is a substrate of Pim-2, and whether Pim-2 survival function can occur in the background of bim deficiency.

By whatever means Pim-2 promotes survival signaling by cytokines, Pim-2 may be considered a target for anticancer drug discovery. Pim-2 is clearly not identical in function to Bcl- $\mathrm{x}_{\mathrm{L}}$, which extends viability, despite a decline in cell metabolism (Plas and Thompson 2002). Rather, Pim-2 acts in a manner more similar to Akt, in that both maintain survival, cell size, and metabolism; however, Pim-2 does not seem to work through the Akt pathway (Fig. 1). Thus, parallel and perhaps overlapping or redundant survival pathways may be activated by growth factors and cytokines. At least two Akt substrates, Bad and the translation inhibitor 4E-BP1, are also phosphorylated by Pim-2 (Fox et al. 2003). The extent of the overlap between the Pim-2 and Akt pathways can be determined with the further elucidation of downstream targets for both (Fig. 1). Finally, as Pim-2 and Akt pathways are activated in human tumors, this may necessitate the search for inhibitors of both pathways to overcome the constitutive and inappropriate survival signaling that is a common property of many human cancers.

\section{Acknowledgments}

I thank Drs. Deirdre Nelson and Kurt Degenhardt for comments and helpful discussions

\section{References}

Adams, J.M., Harris, A.W., Pinkert, C.A., Corcoran, L.M., Alexander, W.S., Cory, S., Palmiter, R.D., and Brinster, R.L. 1985. The c-myc oncogene driven by immunoglobulin enhancers induces lymphoid malignancy in transgenic mice. Nature 318: $533-538$.
Allen, J.D. and Berns, A. 1996. Complementation tagging of cooperating oncogenes in knockout mice. Semin. Cancer Biol. 7: 299-306.

Allen, J., Verhoeven, E., Domen, J., van der Valk, M., and Berns, A. 1997. Pim-2 transgene induces lymphoid tumors, exhibiting potent synergy with c-myc. Oncogene 15: 11331141.

Askew, D.S., Ashmun, R.A., Simmons, B.C., and Cleveland, J.L. 1991. Constitutive c-myc expression in an IL-3-dependent myeloid cell line suppresses cell cycle arrest and accelerates apoptosis. Oncogene 6: 1915-1922.

Bouillet, P., Metcalf, D., Huang, D.C.S., Tarlinton, D.M., Kay, T.W.H., Köntgen, F., Adams, J.M., and Strasser, A. 1999. Proapoptotic Bcl-2 relative bim required for certain apoptotic responses, leukocyte homeostasis, and to preclude autoimmunity. Science 286: 1735-1738.

Bouillet, P., Cory, S., Zhang, L.-C., Strasser, A., and Adams, J.M. 2001. Degenerative disorders caused by Bcl-2 deficiency prevented by loss of its BH3-only antagonist Bim. Dev. Cell 1: 645-653.

Breuer, M.L., Cuypers, H.T., and Berns, A. 1989. Evidence for the involvement of pim-2, a new common proviral insertion site, in progression of lymphomas. EMBO J. 8: 743-748.

Cory, S. and Adams, J.M. 2002. The Bcl2 family: Regulators of the cellular life-or-death switch. Nat. Rev. Cancer 2: 647656.

Datta, S.R., Ranger, A.M., Lin, M.Z., Sturgill, J.F., Ma, Y.C., Cowan, C.W., Dikkes, P., Korsmeyer, S.J., and Greenberg, M.E. 2002. Survival factor-mediated BAD phosphorylation raises the mitochondrial threshold for apoptosis. Dev. Cell 3: 631-643.

Dijkeers, P.F., Birkenkamp, K.U., Lam, E.W.F., Thomas, S.B., Lammers, J.W., Koenderman, L., and Coffer, P.J. 2002. FKHR-L1 can act as a critical effector of cell death induced by cytokine withdrawal: Protein kinase B-enhanced cell survival through maintenance of mitochondrial integrity. $J$. Cell Biol. 156: 531-542.

Eischen, C.M., Weber, J.D., Roussel, M.F., Sherr, C.J., and Cleveland, J.L. 1999. Disruption of the ARF-Mdm2-p53 tumor suppressor pathway in Myc-induced lymphomagenesis. Genes \& Dev. 13: 2658-2669.

Evan, G.I., Whyllie, A.H., Gilbert, C.S., Littlewood, T.D., Land, H., Brooks, M., Waters, C.M., Penn, L.Z., and Hancock, D.C. 1992. Induction of apoptosis in fibroblasts by c-myc protein. Cell 69: 119-128.

Fanidi, A., Harrington, E.A., and Evan, G.I. 1992. Cooperative interaction between c-myc and bcl-2 proto-oncogenes. $\mathrm{Na}$ ture 359: 554-556.

Fox, C.J., Hammerman, P.S., Cinalli, R.M., Master, S.R., Chodosh, L.A., and Thompson, C.B. 2003. The serine/threonine kinase Pim-2 is a transcriptionally regulated apoptotic inhibitor. Genes \& Dev. (this issue).

Lei, K. and Davis, R.J. 2003. JNK phosphorylation of Bim-related members of the Bcl2 family induces Bax-dependent apoptosis. Proc. Natl. Acad. Sci. 100: 2432-2437.

Mikkers, H., Allen, J., Knipscheer, P., Romeyn, L., Hart, A., Vink, E., and Berns, A. 2002. High-throughput retroviral tagging to identify components of specific signaling pathways in cancer. Nat. Genet. 32: 153-159.

Plas, D.R. and Thompson, C.B. 2002. Cell metabolism in the regulation of programmed cell death. Trends Endo. \& Met. 13: 74-78.

Schmitt, C.A., McCurrach, M.E., de Stanchina, E., Wallace-Brodeur, R.R., and Lowe, S.W. 1999. INK4a/ARF mutations accelerate lymphomagenesis and promote chemoresistance by disabling p53. Genes \& Dev. 13: 2670-2677. 
White

Schmitt, C.A., Fridman, J.S., Yang, M., Baranov, E., Hoffman, R.M., and Lowe, S.W. 2002. Dissecting p53 tumor suppressor functions in vivo. Cancer Cell 1: 289-298.

Shinjo, T., Kuribara, R., Inukai, T., Hosoi, H., Kinoshita, T., Miyajima, A., Houghton, P.J., Look, A.T., Ozawa, K., and Inaba., T. 2001. Downregulation of Bim, a proapoptotic relative of Bcl-2, is a pivotal step in cytokine-initiated survival signaling in murine hematopoietic progenitors. Mol. Cell. Biol. 21: 854-864.

Strasser, A., Harris, A.W., Bath, M.L., and Cory, S. 1990. Novel primitive lymphoid tumours induced in transgenic mice by cooperation between myc and bcl-2. Nature 348: 331-333.

van der Lugt, N.M., Domen, J., Verhoeven, E., Linders, K., van der Gulden, H., and Berns, A. 1995. Proviral tagging in E mu-myc transgenic mice lacking the Pim-1 proto-oncogene leads to compensatory activation of Pim-2. EMBO $I$. 14: 2536-2544.

Vaux, D.L., Cory, S., and Adams, J.M. 1988. Bcl-2 gene promotes haemopoietic cell survival and cooperates with c-myc to immortalize pre-B cells. Nature 335: 440-442.

Verbeek, S., van Lohuizen, M., van der Valk, M., Domen, J., Kraal, G., and Berns, A. 1991. Mice bearing the E mu-myc and $\mathrm{E}$ mu-pim-1 transgenes develop pre-B-cell leukemia prenatally. Mol. Cell Biol. 11: 1176-1179.

Weston, C.R., Balmanno, K., Chalmers, C., Hadfield, K., Molton, S.A., Ley, R., Wagner, E.F., and Cook, S.J. 2002. Activation of ERK1/2 by ARaf-1: ER represses Bim expression independently of the JNK or P13K pathways. Oncogene 22: 1281-1293.

Yu, J., Wang, Z., Kinzler, K.W., Vogelstein, B., and Zhang, L. 2003. PUMA mediates the apoptotic response to p53 in colorectal cancer cells. Proc. Natl. Acad. Sci. 100: 1931-1936. 


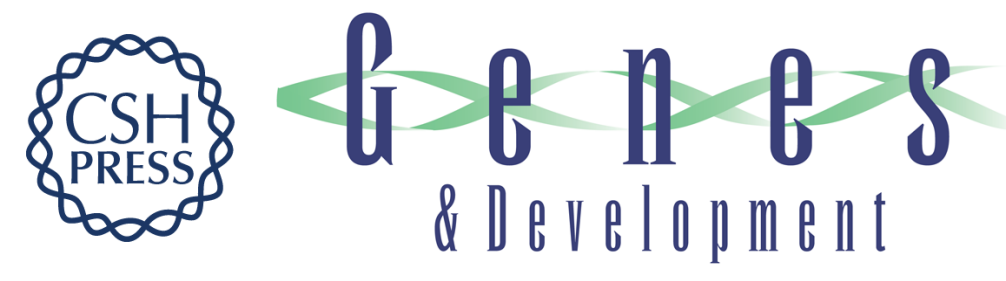

\section{The pims and outs of survival signaling: role for the Pim-2 protein kinase in the suppression of apoptosis by cytokines}

Eileen White

Genes Dev. 2003, 17:

Access the most recent version at doi:10.1101/gad.1123103

References

This article cites 24 articles, 8 of which can be accessed free at:

http://genesdev.cshlp.org/content/17/15/1813.full.html\#ref-list-1

License

Email Alerting

Receive free email alerts when new articles cite this article - sign up in the box at the top

Service right corner of the article or click here.

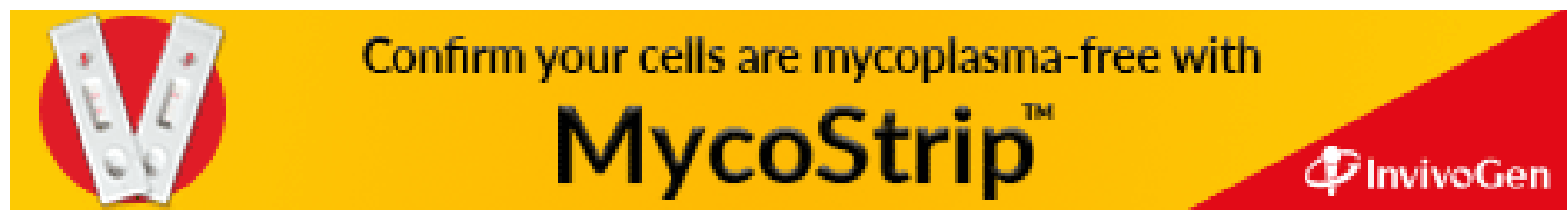

